\title{
Preliminary study of microRNA-126 as a novel therapeutic target for primary hypertension
}

\author{
JIA LIU*, JIAMEI LIU*, LINYING SHI, FAN ZHANG, LIPING YU, XINCHUN YANG and JUN CAI \\ Department of Cardiology, Beijing Chaoyang Hospital, Capital Medical University, Beijing 100020, P.R. China
}

Received August 18, 2016; Accepted October 12, 2017

DOI: $10.3892 / \mathrm{ijmm} .2018 .3420$

\begin{abstract}
The present study aimed to explore microRNA-126 (miR-126) as a novel therapeutic target for primary hypertension. The lentiviral vector containing human immunodeficiency virus 1 (HIV-1), the miR-126 gene knockdown viral vector (lenti-miR-126-KD), and control lentiviral vector (lenti-scramble-miR) were constructed. Spontaneously hypertensive rats were randomly divided into 4 groups, which received a high dose of lenti-miR-126-KD $\left(1 \times 10^{8}, \mathrm{n}=5\right)$, low dose of lenti-miR-126-KD $\left(1 \times 10^{7}, \mathrm{n}=6\right)$, scramble-miR $\left(5 \times 10^{7}\right.$, $n=6)$, and PBS $(n=6)$. Lentiviral vectors were injected into the tail vein. Data on the systolic blood pressure, diastolic pressure, mean arterial pressure, and heart rate were collected weekly. After 8 weeks of virus administration, the distribution of lentiviral vectors in different tissues was observed by fluorescence microscopy. Picric acid Sirius red and H\&E staining were used to observe the target organ damage, and the ELISA kit was used to determine the serum nitric oxide (NO) content. The lentiviral vector was found to be constructed successfully. Eight weeks after the lentiviral vector injection, green fluorescent protein was observed in different tissues in each group. The blood pressure and heart rate were not significantly altered after lentiviral vector injection $(\mathrm{P}>0.05)$. No significant differences in the heart-to-body weight ratio among the four groups were observed $(\mathrm{P}=0.23)$. Picric acid Sirius red and $\mathrm{H} \& \mathrm{E}$ staining revealed that there was no significant difference in morphology among the four groups. No significant difference in the serum NO level among the four groups was noted $(\mathrm{P}=0.23)$. The miR-126 gene knockdown lentiviral vector was constructed successfully. No significant antihypertensive effect was observed by the knockdown of miR-126 for the treatment of primary hypertension. The target
\end{abstract}

Correspondence to: Dr Xinchun Yang or Dr Jun Cai, Department of Cardiology, Beijing Chaoyang Hospital, Capital Medical University, 8 Building Workers Stadium South Road, Chaoyang, Fengtai, Beijing 100020, P.R. China

E-mail: yangxc137@yeah.net

E-mail: greatlj@yeah.net

*Contributed equally

Key words: microRNA-126, primary hypertension, gene therapy organs were not protected significantly after the treatment. The increased level of miR-126 expression in hypertensive patients may be due to a compensatory mechanism.

\section{Introduction}

Essential hypertension is considered to be a highly prevalent pathological condition contributing to the morbidity of crucial risk factors such as cardiovascular disease, cerebrovascular disease, chronic renal failure and increased mortality (1). According to statistics, approximately $90-95 \%$ of the cases of hypertension affecting more than 2 billion adults worldwide are categorized as the essential subtype (2). To date, a large amount of evidence has shown that vasoactive substances such as urotensin II $(3,4)$, endothelin $(5,6)$, and adrenomedullin $(7,8)$ play a major role in the pathophysiology of essential hypertension (9). Therefore, the study of the pathogenesis of hypertension is substantial. Essential hypertension is a multifactorial disease caused by the combined action of several genetic, environmental, and behavioral factors (10). Some studies have attempted to identify the genetic abnormalities (11). However, these results are only 'the tip of the iceberg' in the research of a new field concerning the pathogenesis of hypertension.

MicroRNAs (miRNAs or miRs) are 22-nucleotide non-coding RNA molecules that regulate the expression of other genes by inhibiting translation or cleaving of complementary target messenger RNAs (12), thereby providing a mechanism for protein dose regulation. Five years ago, the discovery of the first miRNA gene, lin-4, in the nematode Caenorhabditis elegans (13), rapidly unraveled the field of miRNA biology. Since then many more of these short regulatory RNA genes have been identified in flowering plants, worms, flies, fish, frogs, and mammals (12). Currently, about $2 \%$ of the known human genes encode miRNAs (14).

miRNAs are transcribed as long RNA precursors (pri-miRNAs) that contain a stem-loop structure of approximately 80 bases (15). Pri-miRNAs are processed in the nucleus by the RNase III enzyme Drosha and DGCR8/Pasha (16), which excise the stem-loop to form the pre-miRNA. These RNA molecules are then exported from the nucleus by Exportin-5 (17) to the cytoplasm, wherein another RNase III enzyme, Dicer, cuts the pre-miRNA to generate the mature miRNA as a part of a short RNA duplex. Subsequently, the RNA is unwound by helicase activity and incorporated into an RNA-induced silencing complex (RISC) (18). The RISC 
directs the gene silencing, where it is enabled to target specific mRNAs through complementary sequences in the 3'-untranslated regions (3'-UTRs) $(19,20)$. The perfect base pairing triggers mRNA degradation through a mechanism similar to that operating during RNA interference (RNAi) induced by small interfering RNAs (siRNAs). On the other hand, miRNAs regulate gene expression by imperfect base pairing to the 3'-UTR of target mRNAs and causing mRNA degradation or inhibiting protein synthesis (21).

The miRNAs expressing in specific tissues consitute a predominant population, which suggests that the miRNAs are highly tissue-specific (22). miR-126 is an endothelial cell-specific miRNA (20). Recent studies have demonstrated the vital roles for miRNAs as a response to injury and stress to the cardiovascular system. This characteristic illustrates that a single miRNA can regulate vascular integrity and angiogenesis $(20,23)$. miR-126 was found to reduce atherosclerosis (24), and can regulate adhesion molecule expression, thereby further controlling vascular inflammation (25). Ding et al demonstrated that the levels of inflammation are significantly enhanced in the early stage of hypertension (26).

Some researches have previously investigated the gene functions associated with hypertension and high blood pressure leading to organ damage $(27,28)$. Previous studies have shown that miR-126 is involved in cardiovascular disease by modulating the transition of endothelial progenitor cells, which is indispensable for the occurrence of hypertension (29-31). Thus, further research by us focused on the relationship between miR-126 and the pathogenesis of hypertension in animal experiments. In the present study, the research process and results of animal experiments are reported.

miR-126 is closely related to endothelial function, and endothelial dysfunction is indispensable for the occurrence of hypertension. Therefore, we hypothesized that dysregulated miR-126 expression impairs endothelial function, resulting in hypertension. However, relevant data have not yet been reported.

RNA interference (RNAi) occurs in normal individuals as a phenomenon of specific inhibition of a target gene. When double-stranded RNAs (dsRNAs) homologous to the endogenous mRNA coding region are introduced into cells, the mRNA degrades resulting in specific gene silencing, thus, playing an important role in cell culture and in vivo studies. Based on the above principles, the present study utilized the lentiviral vector system to integrate the antisense oligonucleotides of miR-126, and thereby knock down the miR-126 expression to treat hypertension through gene therapy strategy.

Taken together, miR-126 is crucial for endothelial function. Since hypertension is closely associated with endothelial dysfunction, we speculated that dysfunctional endothelium caused by abnormal miR-126 expression may play a pivotal role in primary hypertension. Our preliminary investigation used serum samples from 4 healthy individuals and 6 patients with essential hypertension who were comparable in age, sex, and weight. We also found that miR-126 expression was upregulated in the patients with hypertension compared with the healthy controls. Moreover, although miR-126 downregulation through RNAi is theoretically feasible, no evidence has yet been shown for miR-126 application in hypertension therapy. To the best of our knowledge, the present study for the first time elucideated the relationship between miR-126 and human hypertension and is also the first in vivo assessment of the role of miR-126 in hypertension.

\section{Materials and methods}

A total of 4 healthy individuals and 6 patients with essential hypertension from Beijing Chao-Yang Hospital (Beijing, China) were selected for assessment of miRNA expression in our preliminary experiment who were comparable in age, sex, and weight. The present study was approved by the Ethics Committee of Beijing Chaoyang Hospital (reference no. 2009-S-1). All the patients provided written informed consent for the use of their samples for scientific research prior to enrollment. A total of 23 spontaneously hypertensive rats (SHR), 8 weeks of age, were obtained from Capital Medical University Laboratory Animals Research Center (Beijing, China) and acclimatized in a controlled room at $21 \pm 2^{\circ} \mathrm{C}$ and $60 \pm 5 \%$ humidity in which a 12:12 h light:dark cycle was maintained. All the animals were maintained under specific pathogen-free conditions. The study was approved by the Animal Ethics Committee (reference no. 2012/A-99) and was conducted in accordance with the 'Animal Welfare Act and the Guide for the Care and Use of Laboratory Animals (NIH publication no. 5377-3, 1996)'.

Instruments. The instruments used included rat tail-artery non-invasive blood pressure tail-cuff apparatus (BP-98A; Softron, Tokyo, Japan), inverted fluorescence microscope BX51, polarization microscope BH2 (both from Olympus, Tokyo, Japan) and GenePix 4000B Microarray Scanner (Axon Instruments, Union City, CA, USA).

Reagents. The reagents were purchased as follows: TRIzol (Invitrogen Life Technologies, Carlsbad, CA, USA), RNeasy Mini kit (Qiagen, Inc., Valencia, CA, USA), microRNA-126 gene knockdown lentiviral vector, microRNA-126 interference control lentiviral vector (both from Shanghai Shengbo Biotech Co., Ltd., Shanghai, China), nitric oxide (NO) kit (R\&D Systems, Minneapolis, MN, USA), Sirius red F2B stain in carbazotic acid (Sigma, St. Louis, MO, USA), and ELISA kit (R\&D Systems).

miRCURY LNA ${ }^{T M}$ microRNA arrays. Our preliminary investigation reserved the blood samples from healthy individuals and patients with essential hypertension. Total RNA was harvested using TRIzol and RNeasy Mini kit according to the manufacturer's instructions. After having undergone RNA measurement on the NanoDrop instrument, the samples were labeled using the miRCURY ${ }^{\mathrm{TM}} \mathrm{Hy} 3^{\mathrm{TM}} / \mathrm{Hy}^{\mathrm{TM}}$ Power Labeling kit and hybridized on the miRCURY ${ }^{\mathrm{TM}}$ LNA Array (v.11.0). Scanning was performed with the Axon GenePix 4000B Microarray scanner. GenePix Pro v6.0 (Molecular Devices LLC, USA) was used to read the raw intensity of the image.

Construction of the miR-126 gene knockdown lentiviral vector (lenti-miR-126-KD). Cloning and vector construction was carried out as previously described (19). The rno-mir-126 mature sequence was>rno-miR-126 MIMAT0000832; UCGUACCGU GAGUAAUAAUGCG. For gene knockdown, the target gene expression was driven by the U6 promoter. A lentiviral vector for miR-126 gene knockdown was constructed by U6-promoter- 
driven target gene expression. The target sequence was antisense and complementary to the mature miR-126. Primers included: MS2117_1, CCGGCGCATTATTACTCACGGT ACGATTTTTTG; MS2117_2, AATTCAAAAAATCG TACCGTGAGTAATAATGCG. For scramble-miR design, a non-specific DNA sequence was inserted after the U6 promoter. For annealing of the primer pairs, pMagic 4.0 vector was constructed, and MS2117_1 and MS2117_2 primers were used to evaluate the gene knockdown. The scramble-miR was not identified. Vectors were sent for sequencing, and titers of the lentiviral vector were estimated.

miR-126 gene knockdown for hypertension therapy. For the experimental groups, 23 SHRs were randomly divided into 4 groups. The lentiviral vectors were diluted in PBS to a final volume of $350 \mu \mathrm{l}$ and injected through the tail vein into the rats. The high dose group (HD) received lenti-miR-126-KD $\left(1 \times 10^{8}\right)$ injection, $n=5$. The low dose group (LD) received lenti-miR-126-KD $\left(1 \times 10^{7}\right)$ injection, $\mathrm{n}=6$. The scramble miR group received lenti-scramble-miR $\left(5 \times 10^{7}\right)$ injection, $n=6$. As a control, PBS was injected into each mouse, $n=6$.

In regards to the observation index of the experimental animals, the rat tail artery non-invasive blood pressure (BP-98A; Softron) was used to concurrently measure the tail artery systolic pressure, mean blood pressure, diastolic blood pressure, and heart rate in a quiet environment when the rats were awake. The blood pressure of each rat was tested at least 3 times consecutively to obtain an average. Eight weeks of continuous observation was performed, and body weights before and after the dosage were recorded.

In regards to the observation index of organs and blood, heart and body ratio $(\mathrm{Hw} / \mathrm{Bw}), 3 \%$ of pentobarbital sodium was administered at a dose of $0.2 \mathrm{~g} / 100 \mathrm{~g}$ body weight as anesthesia to the rats. The heart weight was measured on electronic scales and $\mathrm{Hw} / \mathrm{Bw}$ was calculated. For tissue sections, the rats were anesthetized using a compound anesthetic (3\% pentobarbital sodium at a dose of $30 \mathrm{mg}$ pentobarbital $/ \mathrm{kg}$ animal body weight). After the removal of the tissues, the rats were sacrificed. For perfusion, the syringe needle penetrated the left ventricle of the heart and opened up the right auricle. A total of $0.9 \%$ saline was used for perfusion until a clear effluent was recovered. For fixation, the perfusion was rapidly carried out through the left ventricle of the heart followed by slow perfusion for $\sim 30 \mathrm{~min}$. The heart, liver, kidneys, lungs and brain were excised from each animal. A total of $36 \mathrm{~h}$ of sedimentation was followed by $4 \%$ paraformaldehyde fixation in $30 \%$ sucrose solution. The brain tissue was directly embedded into n-hexane for 25-26 sec for quick freezing. Regarding the tissue sections, brain tissue was sectioned at the $20 \mu \mathrm{m}$ thickness, whereas all the other tissues were sectioned at a thickness of $14 \mu \mathrm{m}$. Green fluorescence was monitored under a fluorescence microscope for the detection of successful transfection. H\&E staining and occasionally Sirius red F2B in carbazotic acid staining were also performed for heart and kidney histomorphology. For collagen specificity by polarization microscopy, type I collagen fibers were arranged intimately, showing strong birefringence, with yellow or red fibers; type II collagen fiber showed weak birefringence, loose mesh distribution with multiple colors; type III collagen fiber also showed weak birefringence, with green fine fibers; type IV collagen fiber exhibited yellow basi- lemma with weak birefringence. The scale of fibrosis of each group could thus be observed directly and compared to the degree of injury in the target organs of the SHRs.

\section{Roles of miR-126 in hypertension pathogenesis and} progression

Serum sample preparation. A total of $3 \%$ of pentobarbital sodium was used at a dose of $0.2 \mathrm{~g} / 100 \mathrm{~g}$ body weight for rat anesthesia. A total of 6-7 $\mathrm{ml}$ whole blood sample was withdrawn from the cardiac apex before the removal of the tissues by thoracotomy and transferred into yellow capped tubes. The serum samples were collected by centrifugation for 15-20 min at 3,000 rpm.

NO level test. ELISA kit was used, following the manufacture's protocol, to estimate the NO levels.

Biochemical measurements. ELISA was performed to estimate ALB, AST, ALT, CHOL, HDL-C, LDL-C, TG, BUN and $\mathrm{Cr}$ (38 parameters in total). The differences in the biochemical indices among groups were compared.

Statistical analysis. Data were analyzed by SPSS 16.0 (SPSS, Inc., Chicago, IL, USA) and GraphPad Prism 4.0 statistical package. Measurement data are represented as mean \pm standard deviation (mean \pm SD). Normality and homogeneity of variance were tested before comparison: data that fulfilled the normal distribution and homogeneity of variance were analyzed by one-way analysis of variance; for data with the heterogeneity of variance, the logarithm of normality and homogeneity was used for the variance test. Data that did not fulfill the homogeneity criteria were analyzed by Kruskal-Wallis non-parametric test. $\mathrm{P}<0.05$ and $\mathrm{P}<0.01$ were considered to indicate a statistically significant difference.

\section{Results}

miRNA-126 expression level in hypertension. The hypertensive patients demonstrated significantly higher expression of 3'-UTR of miR-126 (1.410 \pm 0.369 vs. $0.838 \pm 0.274, \mathrm{P}=0.03)$ and 5'-UTR of miR-126 $(1.799 \pm 0.490$ vs. $0.997 \pm 0.437, \mathrm{P}=0.03)$ compared with the healthy controls (Fig. 1A). At the same time, the color of the heat map diagram scale shown at the top illustrates the relative expression level of an miRNA in a certain slide: red color represents a higher expression level and green color represents a lower expression level, indicating that miR-126 was upregulated in the patients with hypertension (Fig. 1B).

Construction of the lentiviral vector for miR-126 gene knockdown. The DNA sequencing result for the lentiviral vector for miRNA-126 gene knockdown is demonstrated in Fig. 2. The highlighted areas indicate the antisense sequence complementary to the mature miR-126: 5'-CGCATTATTACTCACGGTACGA-3', indicating successful construction of the lentiviral vector.

miR-126 gene knockdown for hypertension treatment Blood pressure and heart rate. After tail vein injection, changes in the systolic pressure, mean blood pressure, diastolic blood pressure, and heart rate with time were continuously monitored for 8 weeks. The results are summarized in Tables I-IV, and plots are represented in Fig. 3. A statistical significant difference 

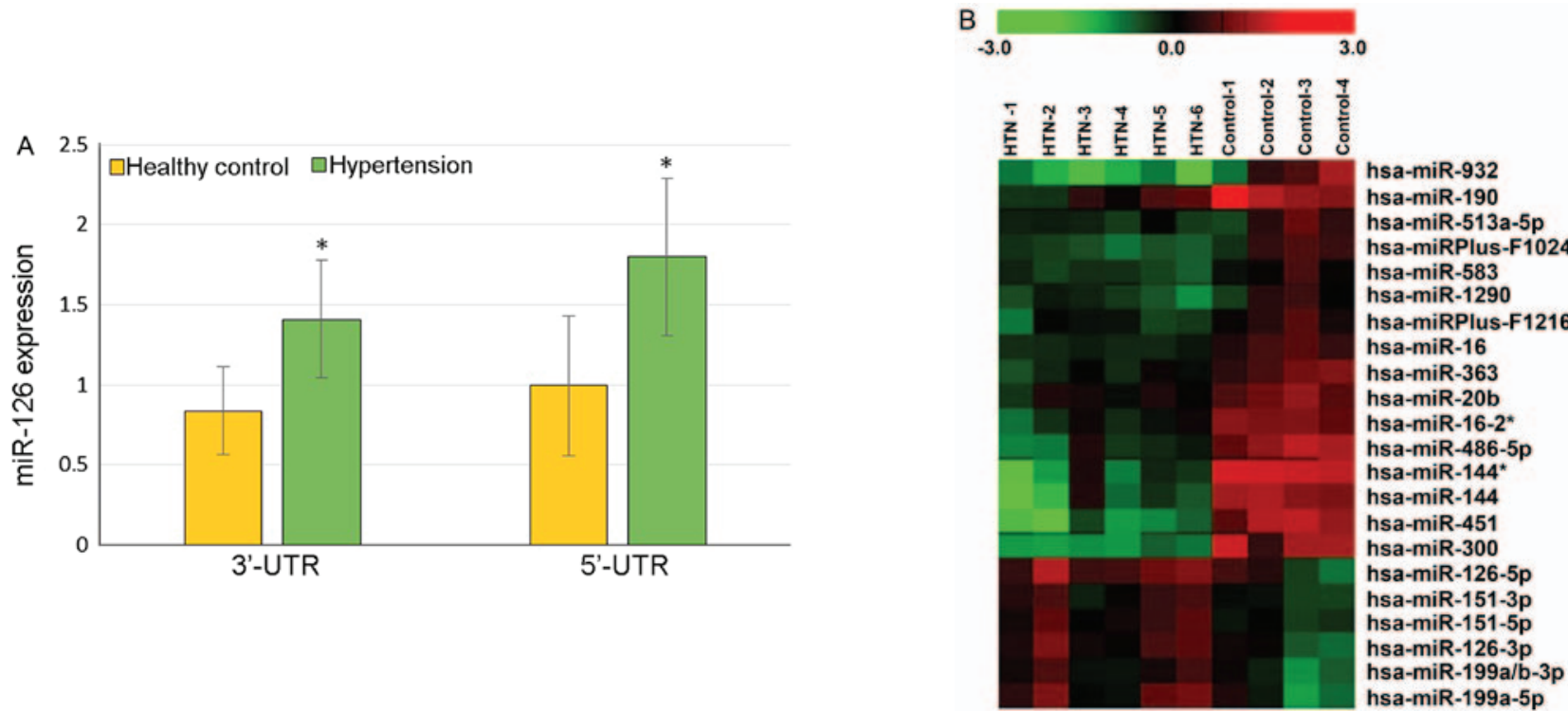

Figure 1. (A) The microRNA-126 expression level in hypertension. The hypertensive patients demonstrated significantly higher 3'-UTR of miR-126 $(1.410 \pm 0.369$ vs. $0.838 \pm 0.274, \mathrm{P}=0.03)$ and 5 '-UTR of miR-126 ( $1.799 \pm 0.490$ vs. $0.997 \pm 0.437, \mathrm{P}=0.03)$ expression levels compared with the healthy controls. ${ }^{\prime} \mathrm{P}<0.05$. (B) MicroRNAs in primary hypertensive patients and healthy controls were detected by gene chips. HTN-1-6, primary hypertensive patients; control 1-4, healthy controls. Red color indicates high expression; green color indicates low expression. UTR, untranslated region.

A $200 \quad 210 \quad 220 \quad 230 \quad 240 \quad 250$

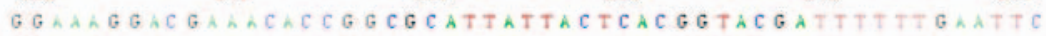
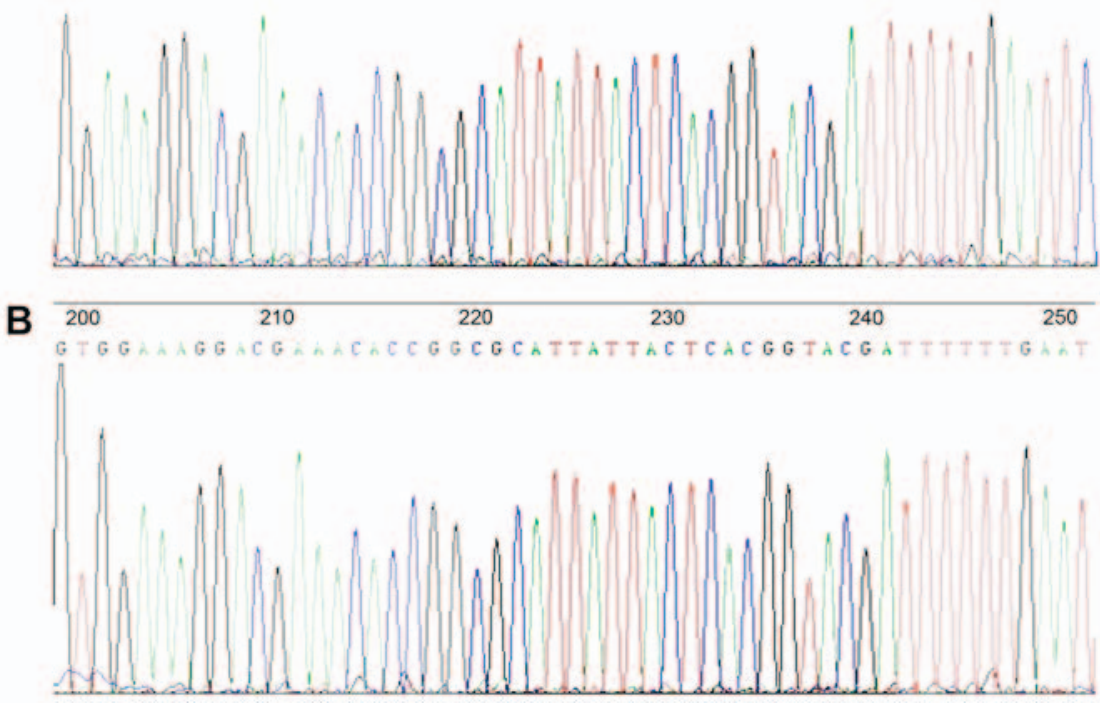

Figure 2. DNA sequencing results of the lentiviral vector for miR-126 gene knockdown. The highlighted areas indicate the antisense sequence completely complementary to the mature miR-126. Sequencing results with primer (A) MS2117_1 and (B) MS2117_2.

was neither observed in the blood pressure among each SHR group before dose $(\mathrm{P}>0.05)$, nor at each time point after the drug administration $(\mathrm{P}>0.05)$, suggesting that the blood pressure was not affected by dose. According to Fig. 3, the heart rates of the HD and LD groups started declining from 4 weeks after drug administration; however, this was not statistically significant $(\mathrm{P}>0.05)$.

Body weight and heart body ratio. As shown in Table $\mathrm{V}$ and Fig. 4, no statistical significance was noted (one-way analysis of variance $\mathrm{P}>0.05$ ).
Green fluorescence of frozen sections. Since the lentiviral vector encodes an eGFP gene, successful transfection of the lentiviral vector can be observed as green fluorescence in the tissue. Although miR-126 has tissue specificity, with high expression in the heart and lung, it is also expressed in brain, liver, and kidney at a low level (15). The lentiviral vector is not topic for organs. It is not only highly expressed in the lung but expressed in all other organs. The GFP is demonstrated in Fig. 5 in all the organs; less in the brain, maximum in the lung. The expression data are consistent with the previous studies, 
Table I. Comparison of the systolic pressure among groups.

\begin{tabular}{|c|c|c|c|c|c|}
\hline Time & $\mathrm{HD}(\mathrm{n}=5)$ & $\operatorname{LD}(n=6)$ & $\begin{array}{l}\text { Scramble-miR } \\
\quad(n=6)\end{array}$ & $\begin{array}{l}\text { Control } \\
(n=6)\end{array}$ & P-value \\
\hline Before dose & $167.32 \pm 8.83$ & $166.67 \pm 7.54$ & $162.62 \pm 9.31$ & $164.95 \pm 9.48$ & 0.809 \\
\hline 1 week after dose & $174.80 \pm 3.12$ & $177.86 \pm 4.31$ & $175.97 \pm 4.32$ & $180.22 \pm 6.77$ & 0.364 \\
\hline 2 weeks after dose & $186.98 \pm 5.34$ & $187.71 \pm 5.30$ & $182.16 \pm 4.42$ & $182.22 \pm 5.45$ & 0.163 \\
\hline 3 weeks after dose & $189.86 \pm 7.73$ & $185.07 \pm 6.96$ & $187.94 \pm 7.21$ & $190.2 \pm 8.99$ & 0.667 \\
\hline 4 weeks after dose & $179.83 \pm 7.06$ & $184.62 \pm 8.93$ & $187.75 \pm 5.65$ & $185.44 \pm 8.20$ & 0.469 \\
\hline 5 weeks after dose & $180.08 \pm 7.18$ & $178.39 \pm 12.39$ & $184.60 \pm 7.69$ & $188.14 \pm 6.24$ & 0.268 \\
\hline 6 weeks after dose & $187.35 \pm 12.50$ & $192.85 \pm 8.44$ & $186.06 \pm 10.89$ & $189.71 \pm 12.53$ & 0.740 \\
\hline 7 weeks after dose & $193.25 \pm 8.39$ & $187.54 \pm 8.11$ & $190.06 \pm 4.51$ & $187.58 \pm 7.01$ & 0.570 \\
\hline 8 weeks after dose & $182.88 \pm 5.33$ & $189.17 \pm 7.12$ & $183.65 \pm 4.29$ & $185.50 \pm 8.03$ & 0.405 \\
\hline
\end{tabular}

$\mathrm{P}>0.05$, no statistically significant difference. $\mathrm{HD}$, high dose; $\mathrm{LD}$, low dose. Data are expressed as mean $\pm \mathrm{SD} ; \mathrm{unit}, \mathrm{mmHg}$.

Table II. Comparison of the mean blood pressure among groups.

\begin{tabular}{|c|c|c|c|c|c|}
\hline Time & $\mathrm{HD}(\mathrm{n}=5)$ & $\operatorname{LD}(n=6)$ & $\begin{array}{l}\text { Scramble-miR } \\
\qquad(\mathrm{n}=6)\end{array}$ & $\begin{array}{c}\text { Control } \\
(n=6)\end{array}$ & P-value \\
\hline Before dose & $143.43 \pm 9.95$ & $140.28 \pm 10.55$ & $135.29 \pm 6.85$ & $139.30 \pm 8.50$ & 0.527 \\
\hline 1 week after dose & $145.44 \pm 9.21$ & $144.39 \pm 6.91$ & $144.18 \pm 9.10$ & $147.04 \pm 8.45$ & 0.926 \\
\hline 2 weeks after dose & $155.88 \pm 13.62$ & $152.46 \pm 6.71$ & $150.15 \pm 3.69$ & $152.32 \pm 5.05$ & 0.698 \\
\hline 3 weeks after dose & $163.25 \pm 10.85$ & $155.92 \pm 8.50$ & $160.70 \pm 6.22$ & $162.52 \pm 9.73$ & 0.520 \\
\hline 4 weeks after dose & $151.25 \pm 7.26$ & $160.12 \pm 7.76$ & $159.64 \pm 8.63$ & $158.69 \pm 14.95$ & 0.563 \\
\hline 5 weeks after dose & $153.60 \pm 5.56$ & $161.94 \pm 8.41$ & $155.68 \pm 7.46$ & $164.25 \pm 12.27$ & 0.221 \\
\hline 6 weeks after dose & $162.29 \pm 7.82$ & $167.37 \pm 5.67$ & $159.58 \pm 6.69$ & $162.80 \pm 10.35$ & 0.409 \\
\hline 7 weeks after dose & $156.58 \pm 5.30$ & $157.74 \pm 4.58$ & $158.00 \pm 10.34$ & $157.04 \pm 9.84$ & 0.992 \\
\hline 8 weeks after dose & $150.40 \pm 4.75$ & $161.25 \pm 9.47$ & $154.18 \pm 6.64$ & $154.74 \pm 6.65$ & 0.182 \\
\hline
\end{tabular}

Data of 2 weeks after the dose do not fulfill homogeneity of variance, Kruskal-Wallis non-parametric test was applied instead. P>0.05, no statistically significant difference. HD, high dose; LD, low dose. Data are expressed as mean \pm SD; unit, $\mathrm{mmHg}$.

Table III. Comparison of diastolic blood pressure among groups.

\begin{tabular}{lcccc}
\hline Time & HD $(\mathrm{n}=5)$ & LD $(\mathrm{n}=6)$ & $\begin{array}{c}\text { Scramble-miR } \\
(\mathrm{n}=6)\end{array}$ & $\begin{array}{c}\text { Control } \\
(\mathrm{n}=6)\end{array}$ \\
\hline Before dose & $131.4 \pm 10.63$ & $127.06 \pm 12.59$ & $121.10 \pm 13.02$ & $127.08 \pm 13.22$ \\
1 week after dose & $130.83 \pm 9.67$ & $128.31 \pm 8.00$ & $129.44 \pm 8.77$ & $130.88 \pm 9.58$ \\
2 weeks after dose & $139.33 \pm 11.17$ & $134.86 \pm 10.17$ & $134.64 \pm 7.82$ & $137.45 \pm 8.58$ \\
3 weeks after dose & $150.33 \pm 11.18$ & $140.19 \pm 8.99$ & $146.92 \pm 7.55$ & $146.70 \pm 11.23$ \\
4 weeks after dose & $137.75 \pm 6.93$ & $147.73 \pm 11.11$ & $145.83 \pm 8.40$ & $145.48 \pm 13.95$ \\
5 weeks after dose & $140.08 \pm 6.71$ & $152.90 \pm 11.04$ & $141.96 \pm 6.11$ & $152.01 \pm 12.89$ \\
6 weeks after dose & $150.31 \pm 9.33$ & $153.72 \pm 7.32$ & $146.22 \pm 12.24$ & $149.62 \pm 13.19$ \\
7 weeks after dose & $138.58 \pm 7.60$ & $143.67 \pm 6.14$ & $141.72 \pm 5.95$ & $142.00 \pm 12.82$ \\
8 weeks after dose & $134.08 \pm 10.22$ & $146.76 \pm 7.80$ & $139.44 \pm 9.58$ & 0.956 \\
& & & 0.539 \\
\hline
\end{tabular}

Data of 7 weeks after the dose do not fulfill homogeneity of variance, Kruskal-Wallis non-parametric test was applied instead. P>0.05, no statistically significant difference. HD, high dose; LD, low dose. Data are expressed as mean \pm SD; unit, $\mathrm{mmHg}$.

indicating successful transfection of the lentiviral vectors, and detectable levels in the SHRs even after experiments.
$H \& E$ and Sirius red $F 2 B$ in carbazotic acid staining. $\mathrm{H} \& \mathrm{E}$ and Sirius red F2B in carbazotic acid staining of the heart and 
Table IV. Comparison of heart rates among groups.

\begin{tabular}{lccccr}
\hline Time & HD $(\mathrm{n}=5)$ & LD $(\mathrm{n}=6)$ & $\begin{array}{c}\text { Scramble-miR } \\
(\mathrm{n}=6)\end{array}$ & $\begin{array}{c}\text { Control } \\
(\mathrm{n}=6)\end{array}$ & P-value \\
\hline Before dose & $425.07 \pm 56.25$ & $399.28 \pm 30.59$ & $412.91 \pm 30.54$ & $425.07 \pm 56.25$ & 0.705 \\
1 week after dose & $389.52 \pm 33.68$ & $400.97 \pm 62.05$ & $403.62 \pm 37.63$ & $389.52 \pm 33.68$ & 0.974 \\
2 weeks after dose & $397.88 \pm 36.72$ & $409.52 \pm 91.75$ & $398.48 \pm 58.01$ & $397.88 \pm 36.72$ & 0.973 \\
3 weeks after dose & $419.91 \pm 40.97$ & $407.85 \pm 23.48$ & $440.32 \pm 59.09$ & $419.91 \pm 40.97$ & 0.538 \\
4 weeks after dose & $378.84 \pm 27.79$ & $412.23 \pm 44.57$ & $437.79 \pm 68.45$ & $378.84 \pm 27.79$ & 0.105 \\
5 weeks after dose & $400.67 \pm 38.67$ & $417.57 \pm 50.22$ & $450.89 \pm 53.38$ & $400.67 \pm 38.67$ & 0.405 \\
6 weeks after dose & $419.62 \pm 45.17$ & $422.95 \pm 41.81$ & $457.44 \pm 86.22$ & $419.62 \pm 45.17$ & 0.365 \\
7 weeks after dose & $391.58 \pm 52.02$ & $401.56 \pm 51.51$ & $473.94 \pm 47.49$ & $391.58 \pm 52.02$ & 0.111 \\
8 weeks after dose & $392.62 \pm 13.94$ & $413.52 \pm 65.57$ & $423.39 \pm 72.69$ & $392.62 \pm 13.94$ & 0.178 \\
\hline
\end{tabular}

$\mathrm{P}>0.05$, no statistically significant difference. $\mathrm{HD}$, high dose; $\mathrm{LD}$, low dose. Data are expressed as mean $\pm \mathrm{SD} ; \mathrm{unit}, \mathrm{mmHg}$.
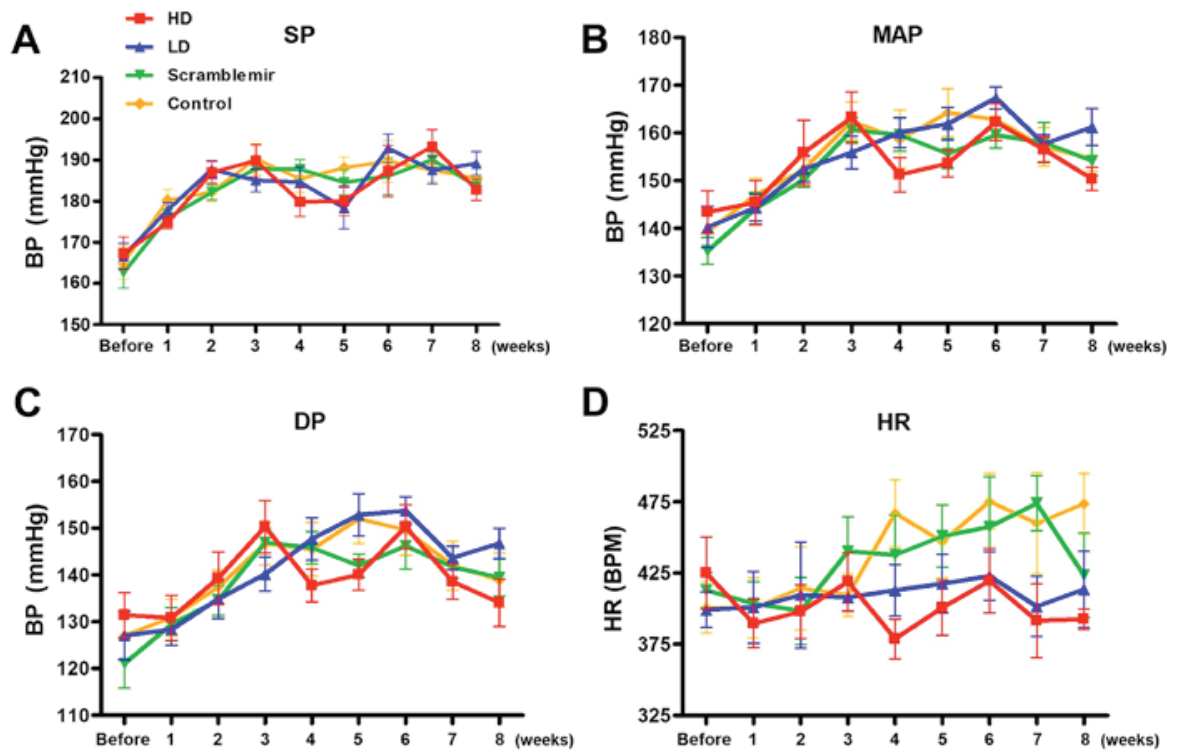

Figure 3. Comparison of (A) systolic pressure (SP), (B) mean blood pressure (MAP), (C) diastolic pressure (BP), and (D) heart rate (HR) among the groups.

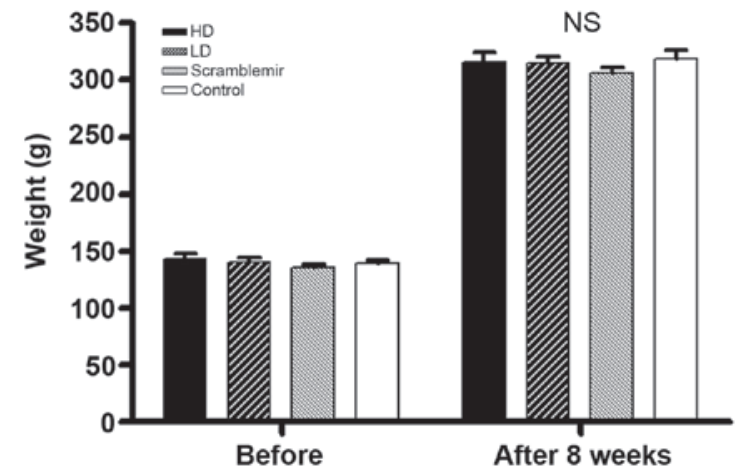

Figure 4. Comparison of body weights among the groups before and after experiments.

kidney are shown in Fig. 6. Although the quantitative analysis was not performed, a difference in the histomorphology was not observed among the groups.
Effects of miR-126 on hypertension pathogenesis and progression. NO and major biochemical criterion of SHR groups are shown in Table VI; no statistical significant difference was noted among the groups $(\mathrm{P}>0.05)$.

\section{Discussion}

The pathogenesis of primary hypertension is complex (1). Genetics, activation of the renin-angiotensin-aldosterone system, and vascular endothelial dysfunction may all be associated with the pathogenesis and progression of hypertension. However, the pathogenesis of primary hypertension remains unknown in nearly $90 \%$ of patients.

RNAi is a biological process of gene silencing induced by dsRNA (including siRNA and miRNA). RNAi interferes with gene translation or transcription to inhibit specific gene expression. Once dsRNA homologous to the endogenous mRNA is induced into a cell, the mRNA degrades resulting in gene silencing (20). Compared to other gene therapies, RNAi 
Table V. Comparison of body weights before and after experiments.

\begin{tabular}{lccc}
\hline Group & $\begin{array}{c}\text { Body weight } \\
\text { before dose }(\mathrm{g})\end{array}$ & $\begin{array}{c}\text { Body weight } \\
\text { after dose }(\mathrm{g})\end{array}$ & $\begin{array}{c}\text { Heart body } \\
\text { ratio }(\mathrm{mg} / \mathrm{g})\end{array}$ \\
\hline HD (n=5) & $143.4 \pm 9.9$ & $316.1 \pm 16.2$ & $4.41 \pm 0.52$ \\
LD (n=6) & $140.3 \pm 10.5$ & $314.6 \pm 15.9$ & $4.06 \pm 0.29$ \\
Scramble-miR & $135.3 \pm 6.8$ & $305.9 \pm 12.0$ & $3.97 \pm 0.20$ \\
$(\mathrm{n}=6)$ & & & \\
Control (n=6) & $139.3 \pm 8.5$ & $318.3 \pm 18.5$ & $4.25 \pm 0.40$ \\
P-value & 0.527 & 0.561 & 0.230 \\
\hline
\end{tabular}

$\mathrm{HD}$, high dose; $\mathrm{LD}$, low dose. Data are expressed as mean $\pm \mathrm{SD}$

is highly specific, with high efficiency and stability $(21,22)$. However, it is primarily used in tumors (23), virus infectious diseases $(24,25)$, and genetic diseases with single gene defects (26). In 2003, Rubinson et al (27) reported successful RNAi in mammalian primary stem cells and transgenic mice by the virus system. It was confirmed that RNAi lowers target gene expression efficiently in vitro (28). Chen et al (32) injected adenovirus-mediated ATIR shRNA into mouse brains for hypertension therapy.

miRNA is an endogenous non-coding RNA, approximately 20-22 nucleotides in length (2). It has been proved that miRNA-126 is endothelium-specific, and has been studied extensively in tumors (33-38) and hematological system diseases $(39,40)$. Our preliminary studies indicated that miR-126 expression was increased in hypertensive patients by miRCURY LNA ${ }^{\mathrm{TM}}$ microRNA arrays. Thus, we hypothesized that there may be a close correlation between miR-126 and the pathogenesis and progression of hypertension. Accordingly, in this study, we focused on the relationship between miRNA-126 and the pathogenesis of hypertension in animal experiments. We inhibited the miR-126 expression by RNAi to explore the possibility of its usage in gene therapy for hypertension and the results of animal experiments were reported.

Lentiviral vector is a retroviral vector with defective replication. The principle of lentiviral vector construction is to separate the cis-acting elements of human immunodeficiency virus 1 (HIV-1) genome and the sequence encoding the trans-acting proteins. This eliminates the virulence gene from the wild-type virus gradually through reconstruction, and completely removes the U3 sequence at the 3' LTR, weakening its transcriptional activation capacity. Thus, a self-inactivating vector system is established. It retains the cis-acting element LTR of the wild-type virus and packaging signals as well as the responding element of the Rev gene, but removes the virulence genes including vif, $v p r, v p u$, and nef, ensuring the biosafety of the vector (41). It stably integrates into the genome of target cells for effective exogenous gene expression without any alterations in the cloned gene. Therefore, the lentiviral vector is widely used to transfer genes due to its high efficiency and stability (42-46). Other retroviral vectors accommodate exogenous genes $<8 \mathrm{~kb}$, which were unfavorable for the present study. The adenovirus is also commonly used as a vector for gene therapy. However, in this case, the target genes are free
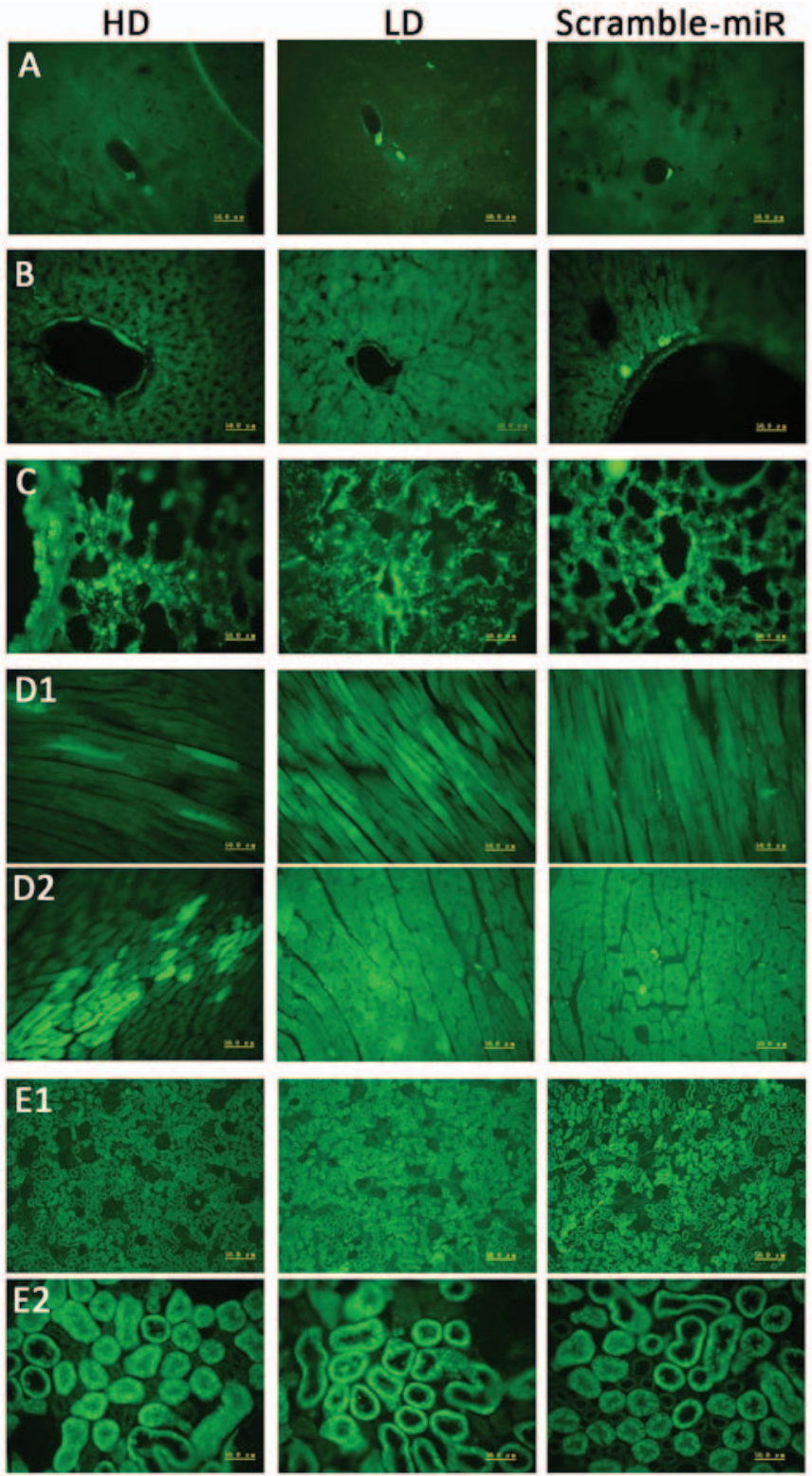

Figure 5. Green fluorescence expression in each organ under fluorescence microscope. 1st column, HD; 2nd column, LD; 3rd column, scramble-miR. (A) Brain, (B) liver, (C) lung, (D1) longitudinal section of cardiac muscle, (D2) cross section of cardiac muscle, (E1) kidney under low power, (E2) kidney under high power. HD, high dose; LD, low dose.

in the nucleus and do not integrate into the chromosomes, thereby impeding long-term expression.

Based on the above features, a lentivirus was adopted as a vector for miR-126 gene knockdown in the present study. Hence, pMagic 4.0 vector with two promoters was used: CMV promoter driving the expression of GFP, resulting in cells with green fluorescence, which is a robust marker for successful gene transfection. The other is the U6 promoter, downstream of which the target gene segment is inserted. For gene knockdown, the target gene segment is complementary to the mature miRNA-126 gene. The sequencing result of the vector construct is shown in Fig. 2, and indicates a successful vector construct. Eight weeks after the in vivo experiment, the heart, kidney, liver, brain, and lung tissue sections were prepared from the SHRs. Green fluorescence was observed in all the cells (Fig. 5), 
Table VI. Comparison of NO and major biochemical criterion of the SHR groups.

\begin{tabular}{|c|c|c|c|c|c|}
\hline Test index & $\mathrm{HD}(\mathrm{n}=4)$ & $\mathrm{LD}(\mathrm{n}=5)$ & $\begin{array}{c}\text { Scramble-miR } \\
\qquad(\mathrm{n}=5)\end{array}$ & $\begin{array}{c}\text { Control } \\
(n=5)\end{array}$ & P-value \\
\hline $\mathrm{NO}(\mu \mathrm{mol} / \mathrm{l})$ & $8.299 \pm 5.001$ & $8.081 \pm 6.353$ & $14.00 \pm 10.01$ & $4.492 \pm 2.055$ & 0.233 \\
\hline $\operatorname{ALB}(\mathrm{g} / \mathrm{l})$ & $16.0 \pm 1.7$ & $16.6 \pm 1.4$ & $17.1 \pm 1.7$ & $18.6 \pm 0.5$ & 0.131 \\
\hline $\mathrm{CHOL}(\mathrm{mmol} / \mathrm{l})$ & $1.74 \pm 0.32$ & $1.59 \pm 0.06$ & $1.69 \pm 0.12$ & $1.64 \pm 0.05$ & 0.552 \\
\hline LDL-C (mmol/l) & $0.22 \pm 0.14$ & $0.14 \pm 0.12$ & $0.15 \pm 0.10$ & $0.06 \pm 0.04$ & 0.280 \\
\hline TG (mmol/l) & $0.27 \pm 0.07$ & $0.22 \pm 0.09$ & $0.28 \pm 0.32$ & $0.29 \pm 0.10$ & 0.601 \\
\hline AST (U/l) & $311.0 \pm 56.7$ & $213.8 \pm 63.4$ & $244.8 \pm 119.8$ & $205.0 \pm 165.6$ & 0.610 \\
\hline ALT (U/l) & $59.3 \pm 8.6$ & $57.6 \pm 8.9$ & $61.4 \pm 13.6$ & $65.3 \pm 9.1$ & 0.764 \\
\hline BUN (mmol/l) & $8.44 \pm 1.20$ & $7.67 \pm 1.30$ & $7.09 \pm 1.27$ & $6.75 \pm 1.57$ & 0.398 \\
\hline CREA $(\mu \mathrm{mol} / 1)$ & $41.1 \pm 4.7$ & $36.7 \pm 11.9$ & $29.9 \pm 3.9$ & $34.4 \pm 3.3$ & 0.244 \\
\hline $\mathrm{Na}^{+}(\mathrm{mmol} / \mathrm{l})$ & $146.2 \pm 2.2$ & $147.9 \pm 1.3$ & $147.3 \pm 1.4$ & $146.3 \pm 1.8$ & 0.422 \\
\hline $\mathrm{K}^{+}(\mathrm{mmol} / \mathrm{l})$ & $6.8 \pm 1.0$ & $6.0 \pm 0.6$ & $6.7 \pm 0.5$ & $6.6 \pm 0.7$ & 0.250 \\
\hline $\mathrm{Ca}^{2+}(\mathrm{mmol} / \mathrm{l})$ & $2.42 \pm 0.04$ & $2.40 \pm 0.12$ & $2.42 \pm 0.11$ & $2.40 \pm 0.06$ & 0.976 \\
\hline
\end{tabular}

NO, nitric oxide; SHR, spontaneously hypertensive rats. HD, high dose; LD, low dose. Data are expressed as mean \pm SD.

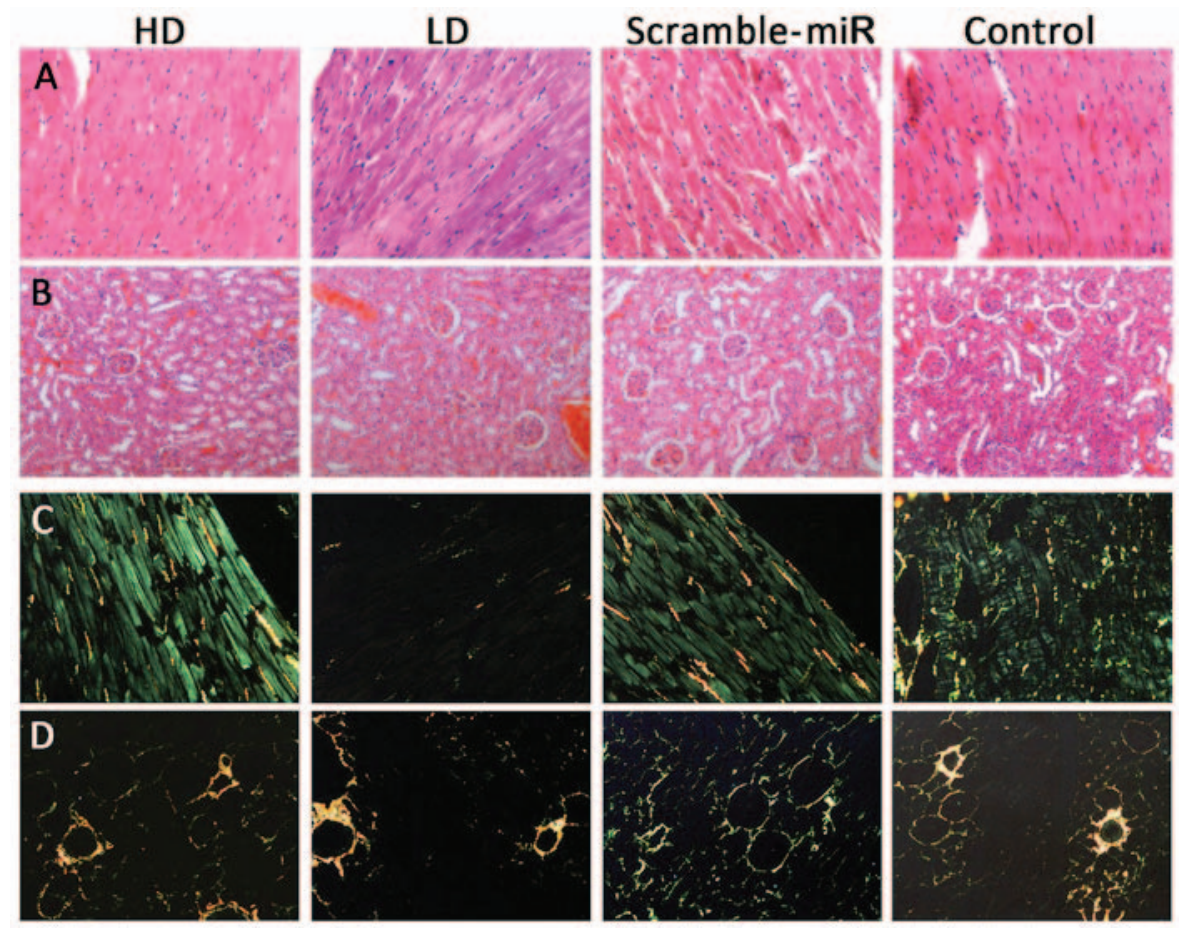

Figure 6. H\&E and Sirius red F2B in carbazotic acid staining of heart and kidney. 1st column, HD; 2nd column, LD; 3rd column, scramble-miR; 4th column, control. (A) H\&E staining of cardiac muscle, (B) H\&E staining of kidney, (C) Sirius red F2B in carbazotic acid staining of cardiac muscle, (D) Sirius red F2B in carbazotic acid staining of kidney. HD, high dose; LD, low dose.

suggesting successful construction of the lentiviral vector and SHR transfection with a detectable expression even after the experiments.

It is considered that inflammation and immune responses are both critical mechanisms for primary hypertension pathogenesis and progression $(47,48)$. Existing data have shown marked upregulated inflammatory factors in the serum of hypertension patients (16). Notably, upregulation of IL-6 and TNF- $\alpha$ was found to lead to vascular endothelial dysfunction and excessive proliferation and migration of vascular smooth muscle cells $(49,50)$. Blocking of the IL-6 or TNF- $\alpha$ inflammatory signaling pathway inhibited Ang II-induced hypertension $(51,52)$. Reduced endothelial nitric oxide synthase (eNOS) activity and NO hyposecretion are crucial for vasomotor dysfunction induced by endothelial malfunction, thereby resulting in hypertension (53). NO is a vital humoral factor which regulates endothelial functions. In vitro studies have confirmed that NO interacts with vascular endothelial growth factor (VEGF), upregulating its mRNA expression. On the other hand, there is a positive feedback from VEGF through 
upregulated eNOS mRNA to promote NO secretion $(54,55)$. Furthermore, increased VEGF synthesis favors the repair of damaged endothelial cells, inhibiting the thickening of impaired intima, thereby improving vascular remodeling. Some studies have shown that in addition to promoting the proliferation of endothelial cells, vascular proliferation, and vascular remodeling, VEGF is closely related to endothelial inflammatory reaction (56-60).

Liu et al found that miR-126 downregulated the VEGF expression in cells and tissues (61). Based on the previous results that miR-126 is highly expressed in hypertensive patients, we speculated that it reduces the expression of endogenous VEGF, weakening the repair of vascular endothelial cells, and therefore, accelerates the thickening of the endangium, resulting in aggravation of vascular remodeling. On the other hand, due to the positive feedback correlation between VEGF and NO, NO production is reduced, limiting vasodilation and ultimately resulting in hypertension.

In the present study, a lentiviral vector with miR-126 gene knockdown sequence was introduced into the rats through tail vein injection. After 8 weeks of continuous observation, measurements of blood pressure, heart rate, and comparison to the control groups, there was no decrease in the blood pressure. In addition, the heart body ratio, histomorphology of heart and kidney, serum NO, and other biochemical criterion did not differ significantly $(\mathrm{P}>0.05)$.

Knockdown of miR-126 neither reduced the blood pressure nor prevented target organ damage. Therefore, miR-126 may potentially serve as a compensatory mechanism in hypertensive patients. Wang et al (12) found that target knockout of miR-126 resulted in angiorrhexis, bleeding, and embryonic mortality. This was due to impaired vascular integrity, defects in endothelial cell division and proliferation or migration, which might be caused by the reduction of angiogenic factor signaling (e.g., VEGF and FGF). However, the regulatory mechanism of angiogenesis signaling cascade amplification remains unclear. Nevertheless, Fish et al (13) demonstrated that miR-126 directly restricts the negative regulatory factors of the VEGF pathway, including Spred-1 protein and phosphoinositol-3 kinase regulatory subunit 2 (PIK3R2/p85- $\beta$ ). For overexpression of Spred-1 or blocking of VEGF signaling in zebrafish, both these pathological phenomena were mimicked by miR-126 gene knockout. These were inconsistent with data from Liu et al (61), which proved that miR-126 enhanced the VEGF pathway and promoted angiogenesis, protecting vascular integrity. Therefore, it may be justified that while under high blood pressure, endothelial function is impaired, activating inflammatory responses, which might promote the compensatory increase in miR-126. Strikingly, this activates the VEGF pathway, promoting endothelial cell proliferation and repair of injured cells, inhibiting thickening of vascular walls, and improving vascular remodeling. On the other hand, since there is a positive feedback relationship between VEGF and NO, activated VEGF may facilitate eNOS to produce NO, reversing the disorder of the renin-angiotensin-aldosterone system.

Although there was no anticipated therapeutic outcome, the present study was the first to elucidate the correlation between miRNA-126 and primary hypertension in human. To the best of our knowledge, this is the first attempt to target miR-126 for hypertension therapeutics. In addition, the miR-126 gene knockdown lentiviral vector was constructed successfully. We speculate that hyper-expression of miR-126 in hypertensive patients is a compensatory mechanism. Taken together, we demonstrated the possible mechanisms of miR-126 during the pathogenesis and progression of hypertension, providing substantial evidence for miR-126 target gene therapy for hypertension.

\section{Competing interests}

The authors declare that they have no competing interests.

\section{References}

1. Liu LS; Writing Group of 2010 Chinese Guidelines for the Management of Hypertension: 2010 Chinese guidelines for the management of hypertension. Zhonghua Xin Xue Guan Bing Za Zhi 39: 579-615, 2011 (In Chinese).

2. Lee RC, Feinbaum RL and Ambros V: The C. elegans heterochronic gene lin-4 encodes small RNAs with antisense complementarity to lin-14. Cell 75: 843-854, 1993.

3. Zhao Y, Samal E and Srivastava D: Serum response factor regulates a muscle-specific microRNA that targets Hand2 during cardiogenesis. Nature 436: 214-220, 2005.

4. Alvarez-Garcia I and Miska EA: MicroRNA functions in animal development and human disease. Development 132: 4653-4662, 2005.

5. Denli AM, Tops BB, Plasterk RH, Ketting RF and Hannon GJ: Processing of primary microRNAs by the Microprocessor complex. Nature 432: 231-235, 2004.

6. Gregory RI, Yan KP, Amuthan G, Chendrimada T, Doratotaj B, Cooch $\mathrm{N}$ and Shiekhattar R: The microprocessor complex mediates the genesis of microRNAs. Nature 432: 235-240, 2004.

7. Lee Y, Ahn C, Han J, Choi H, Kim J, Yim J, Lee J, Provost P, Rådmark O, Kim S and Kim VN: The nuclear RNase III Drosha initiates microRNA processing. Nature 425: 415-419, 2003.

8. Pillai RS, Bhattacharyya SN and Filipowicz W: Repression of protein synthesis by miRNAs: How many mechanisms? Trends Cell Biol 17: 118-126, 2007.

9. Valencia-Sanchez MA, Liu J, Hannon GJ and Parker R: Control of translation and mRNA degradation by miRNAs and siRNAs. Genes Dev 20: 515-524, 2006.

10. Bartel DP: MicroRNAs: Genomics, biogenesis, mechanism, and function. Cell 116: 281-297, 2004.

11. Lagos-Quintana M, Rauhut R, Yalcin A, Meyer J, Lendeckel W and Tuschl T: Identification of tissue-specific microRNAs from mouse. Curr Biol 12: 735-739, 2002.

12. Wang S, Aurora AB, Johnson BA, Qi X, McAnally J, Hill JA, Richardson JA, Bassel-Duby R and Olson EN: The endothelial-specific microRNA miR-126 governs vascular integrity and angiogenesis. Dev Cell 15: 261-271, 2008.

13. Fish JE, Santoro MM, Morton SU, Yu S, Yeh RF, Wythe JD, Ivey KN, Bruneau BG, Stainier DY and Srivastava D: miR-126 regulates angiogenic signaling and vascular integrity. Dev Cell 15: 272-284, 2008.

14. Zernecke A, Bidzhekov K, Noels H, Shagdarsuren E, Gan L, Denecke B, Hristov M, Köppel T, Jahantigh MN, Lutgens E, et al: Delivery of microRNA-126 by apoptotic bodies induces CXCL12-dependent vascular protection. Sci Signal 2: ra81, 2009.

15. Harris TA, Yamakuchi M, Ferlito M, Mendell JT and Lowenstein CJ: MicroRNA-126 regulates endothelial expression of vascular cell adhesion molecule 1. Proc Natl Acad Sci USA 105: 1516-1521, 2008.

16. Stumpf C, John S, Jukic J, Yilmaz A, Raaz D, Schmieder RE, Daniel WG and Garlichs CD: Enhanced levels of platelet P-selectin and circulating cytokines in young patients with mild arterial hypertension. J Hypertens 23: 995-1000, 2005.

17. Cai J, Yi FF, Yang L, Shen DF, Yang Q, Li A, Ghosh AK, Bian ZY, Yan L, Tang QZ, et al: Targeted expression of receptor-associated late transducer inhibits maladaptive hypertrophy via blocking epidermal growth factor receptor signaling. Hypertension 53: 539-548, 2009. 
18. Cai J, Yi FF, Bian ZY, Shen DF, Yang L, Yan L, Tang QZ, Yang $\mathrm{XC}$ and $\mathrm{Li} \mathrm{H}$ : Crocetin protects against cardiac hypertrophy by blocking MEK-ERK1/2 signalling pathway. J Cell Mol Med 13: 909-925, 2009 .

19. Chen CZ, Li L, Lodish HF and Bartel DP: MicroRNAs modulate hematopoietic lineage differentiation. Science 303: 83-86, 2004.

20. Fire A, Xu S, Montgomery MK, Kostas SA, Driver SE and Mello CC: Potent and specific genetic interference by double-stranded RNA in Caenorhabditis elegans. Nature 391: 806-811, 1998

21. Caplen NJ: Gene therapy progress and prospects. Downregulating gene expression: The impact of RNA interference. Gene Ther 11 1241-1248, 2004.

22. Wall NR and Shi Y: Small RNA: Can RNA interference be exploited for therapy? Lancet 362: 1401-1403, 2003.

23. Uchida H, Tanaka T, Sasaki K, Kato K, Dehari H, Ito Y, Kobune M, Miyagishi M, Taira K, Tahara $\mathrm{H}$ and Hamada $\mathrm{H}$ : Adenovirus-mediated transfer of siRNA against survivin induced apoptosis and attenuated tumor cell growth in vitro and in vivo. Mol Ther 10: 162-171, 2004.

24. McCaffrey AP, Nakai H, Pandey K, Huang Z, Salazar FH, Xu H, Wieland SF, Marion PL and Kay MA: Inhibition of hepatitis B virus in mice by RNA interference. Nat Biotechnol 21: 639-644, 2003.

25. Randall G, Grakoui A and Rice CM: Clearance of replicating hepatitis $\mathrm{C}$ virus replicon RNAs in cell culture by small interfering RNAs. Proc Natl Acad Sci USA 100: 235-240, 2003.

26. Ding H, Schwarz DS, Keene A, Affar B, Fenton L, Xia X, Shi Y, Zamore PD and $\mathrm{Xu} Z$ : Selective silencing by RNAi of a dominant allele that causes amyotrophic lateral sclerosis. Aging Cell 2: 209-217, 2003

27. Rubinson DA, Dillon CP, Kwiatkowski AV, Sievers C, Yang L, Kopinja J, Rooney DL, Zhang M, Ihrig MM, McManus MT, et al: A lentivirus-based system to functionally silence genes in primary mammalian cells, stem cells and transgenic mice by RNA interference. Nat Genet 33: 401-406, 2003.

28. Vázquez J, Correa de Adjounian MF, Sumners C, González A, Diez-Freire C and Raizada MK: Selective silencing of angiotensin receptor subtype 1a (AT1aR) by RNA interference. Hypertension 45: 115-119, 2005.

29. Schober A, Nazari-Jahantigh M, Wei Y, Bidzhekov K, Gremse F, Grommes J, Megens RT, Heyll K, Noels H, Hristov M, et al: MicroRNA-126-5p promotes endothelial proliferation and limits atherosclerosis by suppressing Dlk1. Nat Med 20: 368-376, 2014

30. Zhang J, Zhang Z, Zhang DY, Zhu J, Zhang T and Wang C: MicroRNA 126 inhibits the transition of endothelial progenitor cells to mesenchymal cells via the PIK3R2-PI3K/Akt signalling pathway. PLoS One 8: e83294, 2013.

31. Goerke SM, Kiefer LS, Stark GB, Simunovic F and Finkenzeller G: miR-126 modulates angiogenic growth parameters of peripheral blood endothelial progenitor cells. Biol Chem 396: 245-252, 2015.

32. Chen Y, Chen H, Hoffmann A, Cool DR, Diz DI, Chappell MC, Chen AF and Morris M: Adenovirus-mediated small-interference RNA for in vivo silencing of angiotensin ATla receptors in mouse brain. Hypertension 47: 230-237, 2006.

33. Fridman E, Dotan Z, Barshack I, David MB, Dov A, Tabak S, Zion O, Benjamin S, Benjamin $\mathrm{H}$, Kuker $\mathrm{H}$, et al: Accurate molecular classification of renal tumors using microRNA expression. J Mol Diagn 12: 687-696, 2010.

34. Zhang J, Du YY, Lin YF, Chen YT, Yang L, Wang HJ and Ma D: The cell growth suppressor, mir-126, targets IRS-1. Biochem Biophys Res Commun 377: 136-140, 2008.

35. Wang F, Zheng Z, Guo J and Ding X: Correlation and quantitation of microRNA aberrant expression in tissues and sera from patients with breast tumor. Gynecol Oncol 119: 586-593, 2010.

36. Miko E, Czimmerer Z, Csánky E, Boros G, Buslig J, Dezso B and Scholtz B: Differentially expressed microRNAs in small cell lung cancer. Exp Lung Res 35: 646-664, 2009.

37. Li XM, Wang AM, Zhang J and Yi H: Downregulation of miR-126 expression in colorectal cancer and its clinical significance. Med Oncol 28: 1054-1057, 2011.

38. Tavazoie SF, Alarcón C, Oskarsson T, Padua D, Wang Q, Bos PD, Gerald WL and Massagué J: Endogenous human microRNAs that suppress breast cancer metastasis. Nature 451: 147-152, 2008

39. Fulci V, Colombo T, Chiaretti S, Messina M, Citarella F, Tavolaro S, Guarini A, Foà R and Macino G: Characterization of B- and T-lineage acute lymphoblastic leukemia by integrated analysis of MicroRNA and mRNA expression profiles. Genes Chromosomes Cancer 48: 1069-1082, 2009.

40. Cammarata G, Augugliaro L, Salemi D, Agueli C, La Rosa M, Dagnino L, Civiletto G, Messana F, Marfia A, Bica MG, et al: Differential expression of specific microRNA and their targets in acute myeloid leukemia. Am J Hematol 85: 331-339, 2010.
41. Lever AM, Strappe PM and Zhao J: Lentiviral vectors. J Biomed Sci 11: 439-449, 2004.

42. Lois C, Hong EJ, Pease S, Brown EJ and Baltimore D: Germline transmission and tissue-specific expression of transgenes delivered by lentiviral vectors. Science 295: 868-872, 2002.

43. Pfeifer A, Ikawa M, Dayn Y and Verma IM: Transgenesis by lentiviral vectors: Lack of gene silencing in mammalian embryonic stem cells and preimplantation embryos. Proc Natl Acad Sci USA 99: 2140-2145, 2002.

44. Lai $\mathrm{Z}$ and Brady RO: Gene transfer into the central nervous system in vivo using a recombinanat lentivirus vector. J Neurosci Res 67: 363-371, 2002.

45. Zufferey R, Dull T, Mandel RJ, Bukovsky A, Quiroz D, Naldini L and Trono D: Self-inactivating lentivirus vector for safe and efficient in vivo gene delivery. J Virol 72: 9873-9880, 1998.

46. Yu X, Zhan X, D'Costa J, Tanavde VM, Ye Z, Peng T, Malehorn MT, Yang X, Civin CI and Cheng L: Lentiviral vectors with two independent internal promoters transfer high-level expression of multiple transgenes to human hematopoietic stem-progenitor cells. Mol Ther 7: 827-838, 2003.

47. Lifton RP, Gharavi AG and Geller DS: Molecular mechanisms of human hypertension. Cell 104: 545-556, 2001.

48. Wilson EM, Diwan A, Spinale FG and Mann DL: Duality of innate stress responses in cardiac injury, repair, and remodeling. J Mol Cell Cardiol 37: 801-811, 2004.

49. Fernandez-Real JM, Vayreda M, Richart C, Gutierrez C, Broch M, Vendrell J and Ricart W: Circulating interleukin 6 levels, blood pressure, and insulin sensitivity in apparently healthy men and women. J Clin Endocrinol Metab 86: 1154-1159, 2001.

50. Moon SK, Cha BY and Kim CH: ERK1/2 mediates TNF-alphainduced matrix metalloproteinase- 9 expression in human vascular smooth muscle cells via the regulation of NF-kappaB and AP-1: Involvement of the ras dependent pathway. J Cell Physiol 198: 417-427, 2004

51. Coles B, Fielding CA, Rose-John S, Scheller J, Jones SA and O'Donnell VB: Classic interleukin-6 receptor signaling and interleukin- 6 trans-signaling differentially control angiotensin II-dependent hypertension, cardiac signal transducer and activator of transcription-3 activation, and vascular hypertrophy in vivo. Am J Pathol 171: 315-325, 2007.

52. Davis JR, Giardina JB, Green GM, Alexander BT, Granger JP and Khalil RA: Reduced endothelial NO-cGMP vascular relaxation pathway during TNF-alpha-induced hypertension in pregnant rats. Am J Physiol Regul Integr Comp Physiol 282: R390-R399, 2002.

53. Shesely EG, Maeda N, Kim HS, Desai KM, Krege JH, Laubach VE, Sherman PA, Sessa WC and Smithies O: Elevated blood pressures in mice lacking endothelial nitric oxide synthase. Proc Natl Acad Sci USA 93: 13176-13181, 1996.

54. Chin K, Kurashima Y, Ogura T, Tajiri H, Yoshida S and Esumi H: Induction of vascular endothelial growth factor by nitric oxide in human glioblastoma and hepatocellular carcinoma cells. Oncogene 15: 437-442, 1997.

55. Gélinas DS, Bernatchez PN, Rollin S, Bazan NG and Sirois MG: Immediate and delayed VEGF-mediated NO synthesis in endothelial cells: Role of PI3K, PKC and PLC pathways. Br J Pharmacol 137: 1021-1030, 2002.

56. Miska EA, Alvarez-Saavedra E, Townsend M, Yoshii A, Sestan N, Rakic P, Constantine-Paton M and Horvitz HR: Microarray analysis of microRNA expression in the developing mammalian brain. Genome Biol 5: R68, 2004.

57. Chivukula RR and Mendell JT: Circular reasoning: microRNAs and cell-cycle control. Trends Biochem Sci 33: 474-481, 2008.

58. Pan $Q$ and Chegini N: MicroRNA signature and regulatory functions in the endometrium during normal and disease states. Semin Reprod Med 26: 479-493, 2008.

59. Fontana L, Sorrentino A, Condorelli G and Peschle C: Role of microRNAs in haemopoiesis, heart hypertrophy and cancer. Biochem Soc Trans 36: 1206-1210, 2008.

60. Finnegan EJ and Matzke MA: The small RNA world. J Cell Sci 116: 4689-4693, 2003

61. Liu B, Peng XC, Zheng XL, Wang J and Qin YW: MiR-126 restoration down-regulate VEGF and inhibit the growth of lung cancer cell lines in vitro and in vivo. Lung Cancer 66: 169-175, 2009.

This work is licensed under a Creative Commons Attribution-NonCommercial-NoDerivatives 4.0 International (CC BY-NC-ND 4.0) License. 